Journal of Indonesian Tropical Fisheries

ISSN 26554461

Vol. 2, No 1, Juli 2019

Hal 124-135

\title{
ANALISIS SPASIAL-TEMPORAL PENANGKAPAN IKAN PELAGIS DI PERAIRAN
} KABUPATEN BARRU

\author{
Spatial-Temporal Analysis Of Pelagis Fish In The Barru District Water \\ oleh: \\ Muhammad Yusran Lalogau 1), Abdul Rauf ${ }^{2)}$ dan Hasrun ${ }^{3)}$ \\ 1) Mahasiswa Program Studi Manajemen Pesisir dan Teknologi Kelautan PPS UMI Makassar
}

2) Program Studi Ilmu Kelautan FPIK UMI

3) Program Studi Pemanfaatan Sumberdaya Perikanan

Korespondensi: Myusranl@yahoo.co.uk

Diterima: tanggal 23 Februari 2019; disetujui 10 mei 2019

\begin{abstract}
This study aims to conduct spatial and temporal analysis of boat chart fisheries in Barru Regency by (1) mapping potential fishing areas, (2) analyzing the status of fish resource utilization in the Boat chart in Sumpang Binangae Village, Barru Regency. This research was conducted in February-March 2019 in the waters of Barru Regency which is a fishing base boat chart in Sumpang Binangae Village, Barru Regency. The data used are catch data and fishing location data as well as oceanographic data (sea surface temperature and chlorophyll-a concentration) in February and March 2019 collected from the download of Satellite Images, Provincial Fisheries Service statistics from 2007-2017 to Barru Regency area. Analysis of the determination of potential fishing areas with boat charts using geographic information systems (GIS), analyzing the status of utilization of fisheries resources is used analysis of maximum sustainable potential (MSY) and optimum fishing (fopt) by analyzing the effort of catch per unit effort (CPUE). The results showed that Sea surface temperature (SST) in February and March of small pelagic fish in the waters of Barru Regency favored warm waters with a range of SST 28.61 oC - 29.7 oC waters and productivity of Chlorophyll-a range of 0.44-0.0 $94 \mathrm{mg} / \mathrm{m3}$. The highest catch in March is in the waters of the western part of Barru Regency, which is 1391 - $2060 \mathrm{Kg}$. Utilization rate (Tp) Anchovy in the new regency in the last 10 years, namely in 2008 - 2017 has not yet passed JTB so that its utilization still needs to be improved.
\end{abstract}

Keywords : Boat chart; fishing area; small pelagic fish; statu utilization

\section{ABSTRAK}

Penelitian ini bertujuan melakukan analisis spasial dan temporal pada perikanan bagan perahu di Kabupaten Barru dengan cara (1) memetakan daerah potensial penangkapan ikan, (2) menganalisis status pemanfaatan sumberdaya ikan pada bagan Perahu di Kelurahan Sumpang Binangae Kabupaten Barru. Penelitian ini dilaksanakan pada Bulan Februari-Maret 2019 di Perairan Kabupaten Barru. Data yang digunakan adalah data hasil tangkapan dan data lokasi penangkapan ikan serta data oseanografi (sea surface temperature dan konsentrasi klorofil-a) pada Bulan Februari dan Maret tahun 2019 yang dikumpulkan dari hasil download Citra Satelit, data statistik Dinas Perikanan Provinsi Tahun 20072017 untuk wilayah Kabupaten Barru. Analisis penentuan daerah potensial penangkapan ikan dengan bagan perahu digunakan system informasi geografis (SIG), menganalisis status pemanfaatan sumberdaya perikanan digunakan analisis potensi maksimum lestari (MSY) dan penangkapan optimum (fopt) dengan cara menganalisis upaya hasil tangkapan per satuan upaya (CPUE). Hasil penelitian menunjukkan Sea surface temperature (SST) Bulan Februari dan Maret ikan pelagis kecil di perairan Kabupaten Barru menyukai perairan hangat dengan rentang SST $28,61{ }^{\circ} \mathrm{C}-29,7{ }^{\circ} \mathrm{C}$ dan perairan dengan produktivitas kisaran Klorofil-a yaitu $0,44-0,94 \mathrm{mg} / \mathrm{m} 3$. Hasil tangkapan tertinggi pada Bulan Maret berada pada perairan Kabupaten Barru bagian Barat yaitu $1391-2060 \mathrm{Kg}$. Tingkat pemanfaatan (Tp) Ikan teri di kabupaten barru 10 tahun terakhir yaitu tahun 2008 - 2017 belum melewati JTB sehingga masih perlu ditingkatkan pemanfaatannya.

Kata Kunci: Bagan perahu; daerah penangkapan ikan; ikan pelagis kecil; status pemanfaatan 


\section{PENDAHULUAN}

Potensi lestari sumberdaya ikan Indonesia pada tahun 2016 mencapai 9,9 juta ton (Komnas Kajiskan, 2016 dalam Laporan kinerja KKP, 2016). Bahkan pada tahun 2017 telah diberitakan bahwa stok ikan telah mencapai angka 12,5 juta ton, meskipun belum dirilis secara resmi. Potensi tersebut akan menjadi sangat tidak berarti jika tidak dikelola dengan menerapkan pengelolaan perikanan yang bertanggung jawab serta berkelanjutan. Ide awal perikanan berkelanjutan adalah dapat menangkap atau memanen sumber daya ikan pada tingkat yang berkelanjutan, sehingga populasi dan produksi ikan tidak menurun atau tersedia dari waktu ke waktu. Sumber daya ikan termasuk sumber daya yang dapat diperbaharui, walaupun demikian bukan berarti sumber daya ikan dapat dimanfaatkan tanpa batas (Direktorat Kelautan dan Perikanan, 2014).

Produksi ikan pelagis di Kabupaten Barru pada tahun 2011 adalah 9.286,2 Ton, total produksi pada tahun 2012 adalah $8.517,1$ Ton dan total produksi tahun 2013 adalah 9.245,3 Ton. Dari data tersebut potensi perikanan Kabupaten Barru masih sangat besar, Oleh karena itu, pengelolaan pemanfaatan sumberdaya perikanan sangat diperlukan (Pemerintah Kabupaten Barru, 2013) dan memungkinkan masyarakat dapat mengoperasikan berbagai alat tangkap ikan. Salah satu alat tangkap yang banyak dioperasikan di perairan Kabupaten Barru adalah bagan Perahu.

Menjadi penting untuk mendapatkan informasi spasial dan temporal dari suatu alat tangkap agar penyusunan strategi konservasi dan pengelolaan perikanan yang berkelanjutan bisa diterapkan dengan baik. Dalam bidang perikanan, lokasi dimana nelayan biasanya melakukan penangkapan cukup intensif baik secara spasial dan temporal. Tujuan dari penelitian ini adalah untuk memetakan daerah potensial penangkapan ikan dan menganalisis status pemanfaatan sumberdaya ikan.

\section{METODE}

Penelitian ini dilaksanakan di perairan kabupaten Barru yang merupakan fishing base bagan perahu. 
penelitian dilaksanakan pada bulan Februari-Maret 2019.

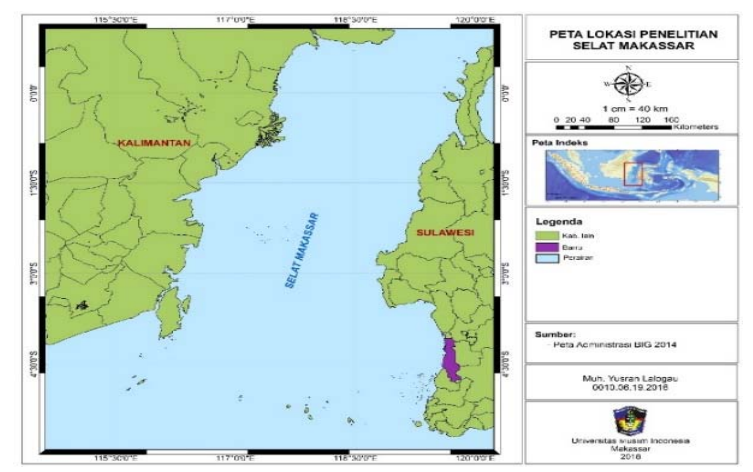

Gambar 1. Peta Lokasi Penelitian

Data primer bersumber dari nelayan bagan di Kelurahan Sumpang Binangae Kabupaten Barru, dengan melakukan pengamatan langsung di lapangan dan dengan wawancara langsung. Data sekunder diperoleh dari Citra Aqua Moddis serta data dari referensi penelitian sebelumnya yang mejadi rujukan.

Data primer dikumpulkan secara intensif dengan menggunakan wawancara terstruktur terhadap nelayan tangkap bagan di Kelurahan Sumpang Binangae Kabupaten Barru. Data sekunder diperoleh dari Citra Aqua Modis serta data dari referensi penelitian sebelumnya yang mejadi rujukan, Ada pula data dari instasi terkait dalam pengelolaan perikanan yaitu data Dinas Perikanan dan data Badan Pusat Statistik.

Dalam penelitian ini subjeknya adalah seluruh nelayan tangkap bagan di kelurahan Sumpang Binangae Kabupaten Barru. Teknik penentuan sampel yang digunakan adalah purposive sampling yaitu cara pengambilan sampel atau penentuan responden dengan menetapkan ciri yang sesuai dengan tujuan (Lynch,1974) dan proportional sampling yaitu pengambilan sampel yang memperhatikan pertimbangan unsurunsur atau kategori dalam populasi penelitian (Rubbin dan Luck,1987), dimana penelitian ini tidak dilakukan pada seluruh populasi, tapi terfokus pada target.

Metode yang digunakan dalam penelitian ini adalah metode survei dengan melihat peta potensial daerah penangkapan ikan bagan perahu, dan analisis pemanfaatan sumberdaya perikanan (CPUE / MSY).

Persamaan untuk mencari nilai CPUE adalah sebagai berikut (Gulland, 1983): 
$\mathrm{CPUE}=\frac{c t}{f t}$

Keterangan :

CPUE $=$ Catch per Unit Effort

$\mathrm{Ct}=$ Hasil tangkapan pada tahun ke-t (ton)

$\mathrm{Ft}$ = Upaya penangkapan pada tahun ke-t (trip)

Nilai daya tangkap kemudian digunakan untuk mencari upaya standar (Standar effort) yaitu dengan mengalikan nilai FPI dan upaya penangkapan alat tersebut.

Persamaan yang digunakan adalah sebagai berikut :

CPUE $=\frac{c t}{f t} \quad$ CPUEs $=\frac{c s}{f s}$
FPIi $=\frac{C P U E i}{\text { CPUEs }}, \ldots \ldots \ldots \ldots \ldots \ldots \ldots \ldots \ldots \ldots \ldots \ldots \ldots \ldots \ldots \ldots \ldots \ldots \ldots$

Standar Efforti $=$ FPIi $\mathrm{x}$ fi

Standart Efforts $=$ FPIs $\mathrm{x}$ fs

Keterangan :

Cs = Hasil tangkapan (catch) per tahun alat tangkap standar (ton)

fs = Upaya penangkapan (effort) per tahun alat tangkap standar (trip)

$\mathrm{Ct}=$ Hasil tangkapan (catch) per tahun jenis alat tangkap lain (ton)

$\mathrm{ft}=$ Upaya penangkapan (effort) per tahun alat tangkap lain (trip)

CPUEs = Hasil tangkapan per upaya penangkapan tahunan alat tangkap standar (ton/trip)

CPUEt $=$ Hasil tangkapan per upaya penangkapan tahunan alat tangkap lain (ton/trip)

FPIs = Faktor daya tangkap jenis alat tangkap standar
FPIt $=$ Faktor daya tangkapan jenis alat tangkap lain

Model Schaefer dan Fox merupakan model analisis regresi dari CPUE terhadap jumlah effort.

a. Model Schaefer :

Hubungan antara C (hasil tangkapan) dan f (upaya penangkapan) adalah :

$$
\mathrm{C}=a f+b(f)^{2}
$$

Nilai Upaya Optimum (fopt) adalah :

$$
\text { fopt }=-(a / 2 b) \text {, }
$$

Nilai Potensi Maksimum Lestari (MSY) adalah :

$$
\mathrm{MSY}=-a 2 / 4 b \text {, }
$$

b. Model Fox

Hubungan antara $\mathrm{C}$ (hasil tangkapan) dan f (upaya penangkapan) adalah :

$$
\mathrm{C}=f \exp (a+b(f),
$$

Nilai Upaya Optimum (f opt) adalah :

$$
\text { Fopt }=-(1 / b) \exp (a-1)
$$

Nilai Potensi Maksimum Lestari (MSY) adalah :

$$
M S Y=-1 / b,
$$

Keterangan :

$\mathrm{C}=$ Jumlah hasil tangkapan per satuan upaya penangkapan (ton/trip)

$$
\begin{array}{ll}
\mathrm{a} & =\text { Intercept } \\
\mathrm{b} & =\text { Slope } \\
\mathrm{f} & =\text { Upaya penangkapan (trip) pada } \\
\text { periode } & \text { ke-i. }
\end{array}
$$

fopt = Upaya penangkapan optimal (trip)

MSY = Nilai potensi maksimum lestari (ton/tahun). 
Persamaan dari tingkat pemanfaatan adalah (Paully 1983 dalam Astuti, 2005):

$$
\mathrm{TPc}=\frac{C i}{M S Y} \times 100 \%
$$

Keterangan :

$\mathrm{TPc}=$ Tingkat pemanfaatan pada tahun ke-I (\%)

$\mathrm{Ci}=$ Hasil tangkapan ikan pada tahun ke-I (ton)

MSY = Maximum Sustainable Yield (ton)

Persamaan dari Tingkat

Pengupayaan adalah :

$$
\mathrm{TPf}=\frac{f s}{f o p t} \times 100 \%
$$

Keterangan :

$\mathrm{TP}=$ Tingkat Pengupayaan pada tahun ke-i (\%)

fs = Upaya Penangkapan (Effort Standar) pada tahun ke-i (trip)

fopt $=$ Upaya Penangkapan Optimum (ton/thn)

\section{HASIL DAN PEMBAHASAN}

\section{Daerah Potensial Penangkapan Ikan}

Daerah potensial penangkapan ikan diperoleh dari hasil overlay dua citra yakni SPL dan klorofil-a yang disatukan dan akan terbentuk peta baru dengan spesifik informasi mengenai daerah penangkapan ikan yang produktif yang dikenal dengan zona optimum penangkapan ikan (Jufri, 2014).

Kisaran optimum dua citra tersebut dapat dijadikan sebagai kombinasi dua karaketristik habitat ikan pelagis kecil. Hasil overlay terhadap hasil tangkapan pada bulan Februari (Gambar 2) terlihat hampir seluruhnya berada di daerah potensial penangkapan ikan (zona optimum) dengan jumlah hasil tangkapan yang lebih banyak yaitu antara 165 - $1130 \mathrm{Kg}$.

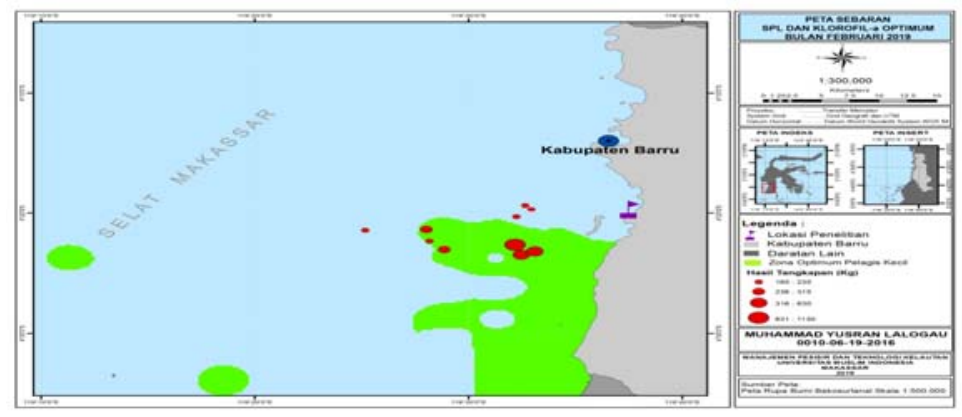

Gambar 2. DPI Pontensial untuk penangkapan ikan pelagis kecil berdasarkan nilai preferensi parameter klorofil-a dan SPL yang diperoleh dari citra satelit MODIS pada bulan Februari 2019 di Perairan Kabupaten Barru.

Bulan Maret menunjukkan adanya perubahan wilayah zona optimum yang secara spasial bergerak ke arah tengah dari perairan Kabupaten Barru. Hasil overlay terhadap hasil tangkapan terlihat seluruhnya berada di wilayah zona optimum dengan jumlah hasil tangkapan yang lebih banyak dari bulan sebelumnya yaitu antara 170 $2060 \mathrm{Kg}$. 


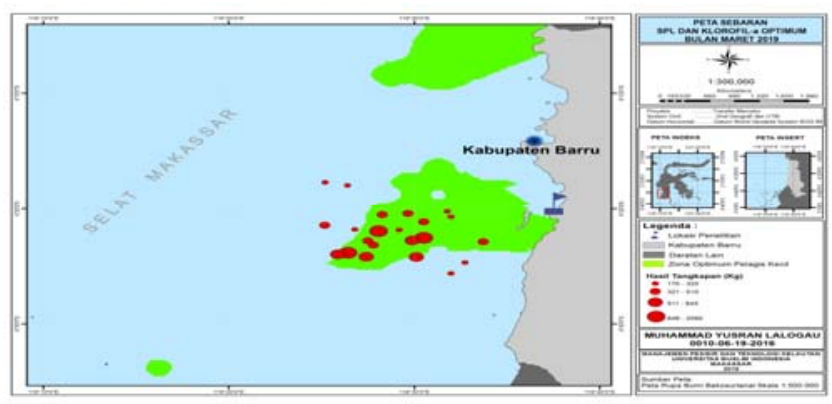

Gambar 3. DPI Potensial untuk penangkapan ikan pelagis kecil berdasarkan nilai preferensi parameter klorofil-a dan SPL yang diperoleh dari citra satelit MODIS pada bulan Maret 2019 di Perairan Kabupaten Barru

Hasil menunjukkan bahwa sebaran SPL dan Klorofil -a Optimum sesuai dengan data sebaran penangkapan. Pada bulan Maret, hasil tangkapan tertinggi berada pada perairan Kabupaten Barru bagian barat yaitu sebanyak 640 - $2060 \mathrm{Kg}$. Hal ini sesuai dengan nilai SPL dan konsentrasi klorofil-a optimumnya yang ditandai dengan warna hijau. Nilai SPL dan konsentrasi klorofil-a optimum adalah nilai dimana SPL dan konsentrasi klorofil-a yang cocok untuk ikan pelagis kecil.

Status pemanfaatan sumberdaya ikan pada bagan Perahu di Kelurahan Sumpang Binangae Kabupaten Barru.
Produksi Hasil Tangkapan Ikan Teri (Ton) dengan alat tangkap Bagan Perahu

Estimasi potensi tangkapan lestari dari data dinas Kelautan dan Perikanan Kab. Barru wawancara dengan nelayan penangkap ikan teri. Data Statistik Perikanan Propinsi Sulawesi Selatan 2008 - 2017, alat tangkap yang dioperasikan di Perairan Kabupaten Barru yang menangkap ikan teri adalah Bagan perahu. Produksi hasil tangkapan ikan teri terbanyak diperoleh dari alat tangkap bagan perahu sebanyak 9655,6 ton pada tahun 2014 dan yang terendah sebesar 3347,8 ton pada tahun 2017, (Tabel 1 dan Gambar 4).

Tabel 1. Hasil Tangkapan Ikan teri (Ton) dengan alat tangkap bagan perahu (Unit) di Kabupaten Barru Periode Waktu 2008 - 2017.

\begin{tabular}{|c|r|c|}
\hline Tahun & Produksi ikan teri (Ton) & Bagan perahu (unit) \\
\hline 2008 & 5697,9 & 40 \\
\hline 2009 & 6528,7 & 60 \\
\hline 2010 & 6692,3 & 57 \\
\hline 2011 & 7574,3 & 55 \\
\hline 2012 & 8154,6 & 87 \\
\hline 2013 & 7587,3 & 53 \\
\hline
\end{tabular}




\begin{tabular}{|l|r|r|}
\hline 2014 & 9655,6 & 53 \\
\hline 2015 & 3577,7 & 51 \\
\hline 2016 & 3949,5 & 51 \\
\hline 2017 & 3347,8 & 53 \\
\hline
\end{tabular}

(Laporan Statistik DKP Provinsi Sulawesi Selatan)

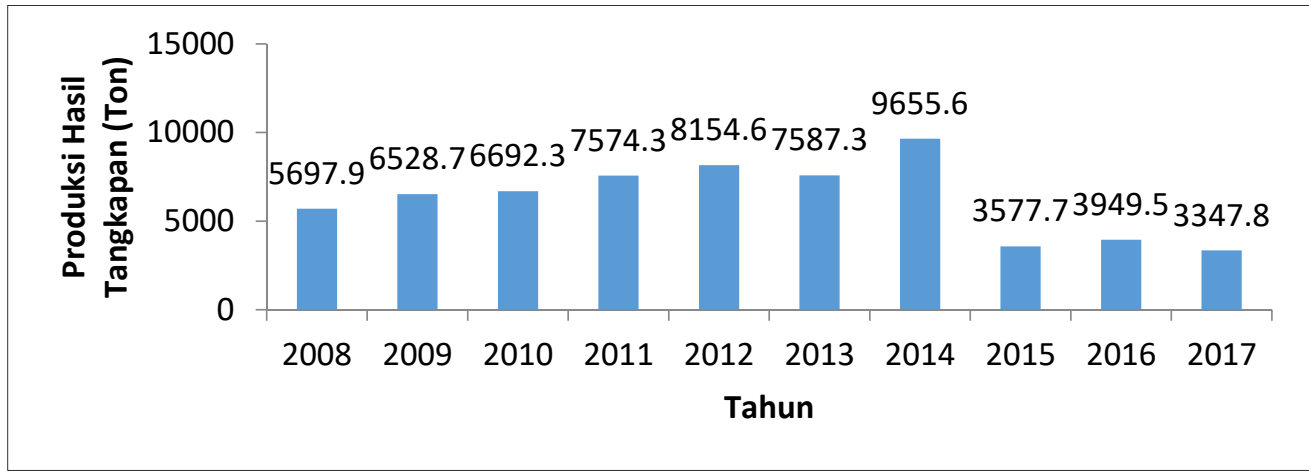

Gambar 4. Grafik Hubungan antara Produksi hasil tangkapan (Ton) Ikan teri Terhadap Jenis Alat Tangkap bagan perahu Periode Tahun 2008 Tahun 2017

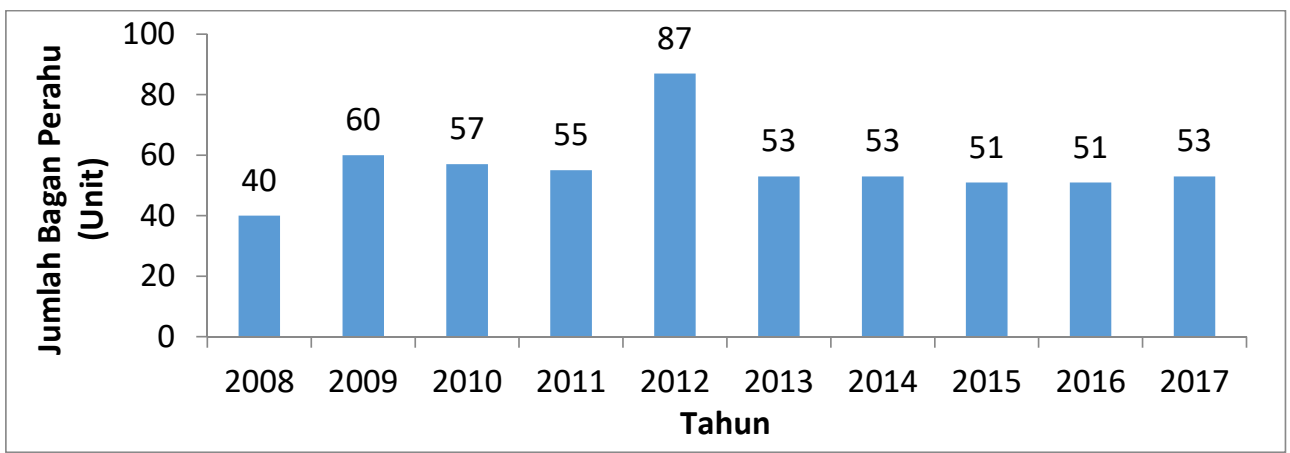

Gambar 5. Grafik Hubungan antara Jumlah Alat Tangkap bagan perahu Periode Tahun 2008 -Tahun 2017 kabupaten barru

Grafik di atas menunjuukkan produksi hasil tangkapan dan upaya peanangkapan alat tangkap bagan perahu di Kab. Barru dari tahun 2008 2017. Dari grafik di atas produksi hasil tangkapan tertinggi terdapat pada tahun 2014 sebanyak 9655 ton dan terendah pada tahun 2017 sebanyak 3347 ton. Sedangkan Upaya penangkapan (unit) ikan teri yang didaratkan di Kab. Barru setiap tahunnya berdasarkan data statistik Kabupaten barru mulai periode tahun 2008 - 2017, memperlihatkan adanya penurunan dan kenaikan upaya penangkapan (unit) ikan teri. Upaya penangkapan (unit) ikan teri tertinggi terjadi pada tahun 2012 dengan jumlah 87 unit dan yang terendah terjadi pada tahun 2008 dengan jumlah 40 unit Peningkatan produksi penangkapan pada tahun 2014 tidak diiringi dengan bertambahnya jumlah unit penangkapan pada tahun 2014, hal ini bisa disebabkan oleh faktor lain, antara lain 
jumlah upaya penangkapan (trip) sedangkan pada tahun 2012 jumlah unit penangkapan yang meningkat tidak diiringi dengan produksi penangkapan yang bertambah, hal ini bisa di sebabkan karena upaya penangkapan yang (Trip) meningkat.

\section{Model Produksi Surplus Metode Schaefer (1954)}

Hasil tangkapan ikan teri (C) dalam satuan ton, upaya penangkapan (F) dalam satuan Unit serta tangkapan per satuan upaya CPUE dalam satuan ton/unit disajikan pada (Tabel 3). Hubungan parabolik antara hasil keseimbangan dan upaya penangkapan optimum akan memberikan informasi mengenai hasil tangkapan maksimum lestari MSY dan tingkat penangkapan optimum FMSY yang akan menghasilkan MSY. Adapun tangkapan per satuan upaya CPUE diperoleh dari hasil bagi antara tangkapan (C) dengan upaya tangkapan (F) setiap tahunnya dari tahun 2008 sampai tahun 2017.

Tabel 3. Jumlah hasil Tangkapan ikan teri (C), jumlah upaya penangkapan (F) dan jumlah tangkapan per satuan upaya (CPUE) ikan teri di Kabupaten Barru.

\begin{tabular}{|r|r|r|r|}
\hline Tahun & Produksi (Ton) & Effort (unit) & CPUE (Ton/unit) \\
\hline 2008 & 5697,9 & 40 & 142,45 \\
\hline 2009 & 6528,7 & 60 & 108,81 \\
\hline 2010 & 6692,3 & 57 & 117,41 \\
\hline 2011 & 7574,3 & 55 & 137,71 \\
\hline 2012 & 8154,6 & 87 & 93,73 \\
\hline 2013 & 7587,3 & 53 & 111,58 \\
\hline 2014 & 9655,6 & 53 & 182,18 \\
\hline 2015 & 3577,7 & 51 & 70,15 \\
\hline 2016 & 3949,5 & 51 & 77,44 \\
\hline 2017 & 3347,8 & 53 & 63,17 \\
\hline
\end{tabular}

(Diolah oleh dari Statistik DKP Provonsi Sulawesi Selatan).

Upaya optimum model Schaefer dapat diperoleh dengan mensubtitusi nilai koefisien regresi $a=150,41$ dan $b=$ $-0,66$.

Berdasarkan model Schaefer, selama satu tahun jumlah unit upaya tangkapan tidak boleh melebihi 114 unit. Menurut model Schaefer, untuk dapat memanfaatkan sumberdaya ikan teri secara lestari di Kabupaten Barru, maka potensi ikan teri yang boleh ditangkap selama satu tahun maksimal 8608,62 ton. Artinya hasil tangkapan maksimum lestari atau MSY ikan teri di Kabupaten Barru sebesar 8608,62 ton, dengan dugaan upaya penangkapan optimum 114 unit selama satu tahun. 


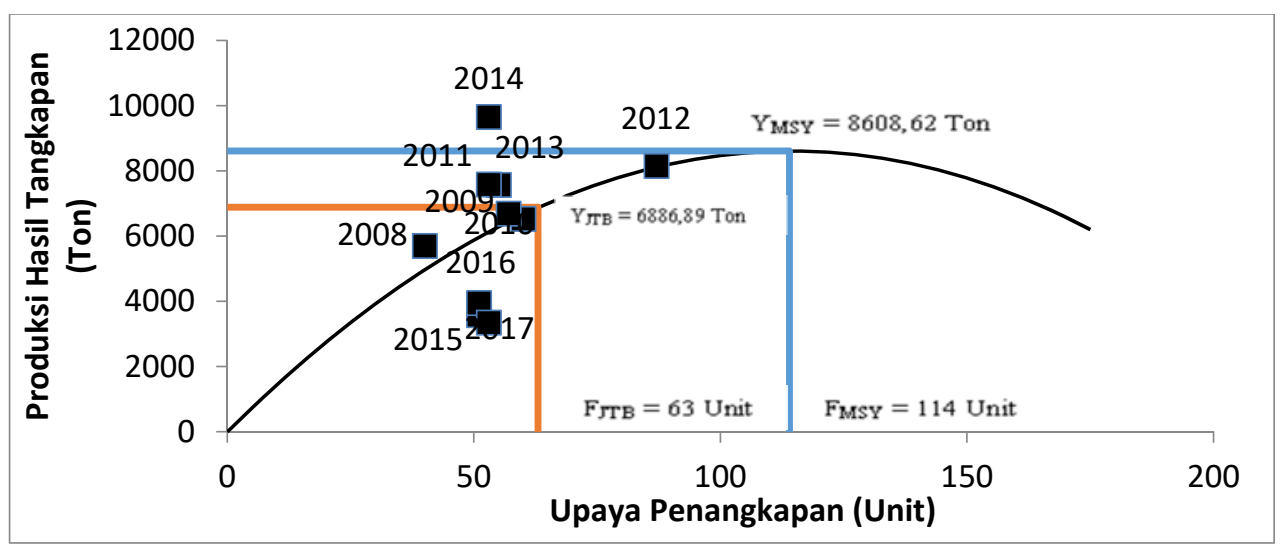

Gambar 6. Kurva hubungan jumlah tangkapan (C) dan jumlah upaya penangkapan (F) ikan teri di Kabupaten Barru berdasarkan model Schaefer.

Berdasarkan data produksi ikan teri dalam kurun waktu 10 tahun terakhir (2008 - 2017) produksi lestari perikanan atau Maximum sustainable Yield (MSY) dengan metode surplus produksi dari schaefer dpat diketahui bahwa nilai potensi lestari serta upaya optimum ikan teri di kabupaten barru sehingga dapat ditentukan status pemanfaatannya dengan membandingkan upaya penangkapan dan hasil tangkapan setiap tahunnya. Berdasarkan model scaefer, didapatkan nilai upaya penangkapan optimum sebesar 114 unit dengan nilai jumlah hasil tangkapan sebebsar 8708,62 ton per tahun. Jika dilihat dari nilai tangkapan maksimum lestari, jumlah tangkapan dari 2008 - 2017 , hanya pada tahun 2012 yang melebihi MSY sedangkan pada tahun lainnya belum melebihi MSY. Pada tahun 2012 sudah melebih MSY sehingga pada tahun selanjutnya terjdi pengurangan atau penurunan upaya penangkapan untuk mengantisapasi terjadinya overfishing pada tahun selanjutnya sedangkan unit penangkapan pada tahun 2008 - 2017 belum melebihi FMSY.

Perbandingan jumlah tangkapan aktual dengan jumlah tangkapan lestari model Schaefer perikanan ikan teri di Kabupaten Barru.

Hasil tangkapan aktual dan hasil tangkapan dengan model Schaefer dari tahun 2008-2017 diperlihatkan pada (Gambar 7). Pola perubahan hasil tangkapan dengan model Schaefer jauh lebih rendah dibandingkan hasil tangkapan aktual selama periode 2008 sampai 2014. 


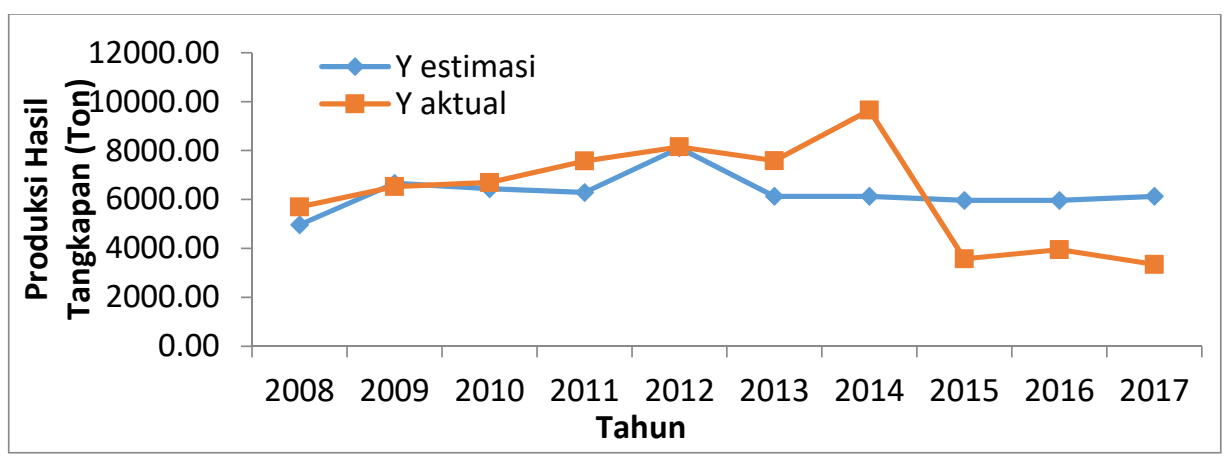

Gambar 18. Perbandingan jumlah tangkapan aktual dengan jumlah tangkapan lestari model Schaefer perikanan ikan teri di Kabupaten Barru.

Produksi hasil tangkapan aktual dan produksi hasil tangkapan dengan model Schaefer dari tahun 2005 sampai tahun 2014, (Gambar 18). Pola perubahan produksi hasil tangkapan tahunan aktual berbeda dengan perubahan produksi tahunan dari model Schaefer. Produksi hasil tangkapan dengan model Schaefer pada tahun 2008 sampai tahun 2014 berada lebih rendah dibandingkan dengan produksi hasil tangkapan aktual nelayan penangkap ikan teri di kabupaten barru. Tahun 2015, tahun 2016, tahun 2017, berada lebih rendah jika dibandingkan dengan produksi hasil tangkapan estimasi nelayan penangkap ikan teri. Tren penurunan jumlah produksi hasil tangkapan terlhat bahwa pada 7 tahun pertama sebesar $6 \%$, setelah itu terjadi tren peningkatapan produksi hasil tangkapan sebesar $78 \%$ pada 3 tahun. Hal ini membuktikan bahwa eksploitasi sumbadaya ikan teri dilakukan terus menerus hingga melawati batas MSY pada tahun 2014 dan eksploitasinya menurun kembali setelah tahun 2015.
Eksploitasi yang berlebih ini di sebabkan adanya penambahan unit alat tangkap cukup tinggi Permintaan ikan teri yang tinggi dapat berdampak pada pemanfaatan stok secara tidak efisien, sehingga dapat menyebabkan kerawanan kelestarian ikan teri.

\section{Tingkat pengupayaan dan pemanfaatan ikan teri}

Berdasarkan analisis Tingkat Pemanfaatan (TP) sumberdaya ikan teri di dapatkan dengan membandingkan produksi hasil tangkapan (catch) dengan jumlah tangkapan yang diperbolehkan (JTB), dan tingkat pengupayaan (TPu) di tentukan dengan membandingkan jumlah upaya penangkapan (unit) dengan jumlah upaya penangkapan optimum ( $\mathrm{f}_{\mathrm{MSY}}$ ).

Tingkat Pemanfaatan (TP) dan tingkat pengupayaan (TPu) ikan teri di perairan Sulawesi Selatan menurut model Schaefer disajikan pada (Tabel 5). Tingkat Pemanfaatan (TP) ikan teri selama 10 tahun pertama belum melebihi tingkat pemanfaatan yang diperbolehkan (JTB) yaitu pada tahun 
2008, tahun 2009, tahun 2010, tapi tahun 2011 tahun 2012, tahun 2013 dan tahun 2014 sudah dalam kondisi underexploited. Tahun 2015 tingkat pemanfaatan (TP) ikan teri terjadi penurunan hingga tahun 2017 sebesar $15,87 \%$ dari JTB.

Tingkat pengupayaan (TPu) alat tangkap untuk pengeksploitasi ikan teri diperoleh hasil selama tujuh tahun pertama belum melebihi tingkat upaya maksimum lestari ( f $\mathrm{JTB}_{\text {) }}$ ikan teri yaitu pada tahun 2008, tahun 2009, tahun 2010, dan tahun 2011, Tahun 2012 tingkat pengupayaan (TPU) telah melebihi tingkat upaya maksimum lestari (f $\left.f_{\text {Jтв}}\right)$ sebesar 38,10\%. Hasil analisis tingkat pemanfaatan (TP) dan Tingkat pengupayaan

(Tpu) menunjukkan bahwa 3 tahun pertama menunjukkan bahwa tingkat eksploitasi ikan teri masih dalam kondisi underexploited. Setelah itu terjadi overfishing pada tahun 2011, tahun 2012, tahun 2013 dan 2014 dengan tingkat pengupayaannya (Tpu) yang telah melebihi $9,98 \%, 18,41 \%, 10,17 \%$ dan 140,20\%, tahun 2012 dengan tingkat pemanfaatnnya (TP) telah melebihi $38,10 \%$.

Tabel 4. Tingkat Pemanfaatan (TP) dan Tingkat Pengupayaan (TPu) Ikan teri (P.Versicolor) di Perairan Kabupaten Barru Model Schaefer Periode Tahun 2008 - Tahun 2017

\begin{tabular}{|r|r|r|r|r|r|r|r|}
\hline Tahun & $\begin{array}{c}\text { Produksi } \\
\text { (Ton) }\end{array}$ & $\begin{array}{c}\text { Effort } \\
\text { (Unit) }\end{array}$ & $\begin{array}{c}\text { CPUE } \\
\text { (Ton/Unit) }\end{array}$ & $\begin{array}{c}\mathrm{F}_{\text {ytb }} \\
\text { (Unit) }\end{array}$ & $\begin{array}{c}\mathrm{Y}_{\text {jtb }} \\
\text { (Ton) }\end{array}$ & $\begin{array}{c}\text { Tingkat } \\
\text { Pemanfaat } \\
\text { an (TP) } \\
(\%)\end{array}$ & $\begin{array}{c}\text { Tingkat } \\
\text { Pengupayaan } \\
(\mathrm{TPu}) \\
(\%)\end{array}$ \\
\hline 2008 & 5697,9 & 40 & 142,45 & 63 & 6886,89 & 82,74 & 63,49 \\
\hline 2009 & 6528,7 & 60 & 108,81 & 63 & 6886,89 & 94,80 & 95,24 \\
\hline 2010 & 6692,3 & 57 & 117,41 & 63 & 6886,89 & 97,17 & 90,48 \\
\hline 2011 & 7574,3 & 55 & 137,71 & 63 & 6886,89 & 109,98 & 87,30 \\
\hline 2012 & 8154,6 & 87 & 93,73 & 63 & 6886,89 & 118,41 & 138,10 \\
\hline 2013 & 7587,3 & 53 & 111,58 & 63 & 6886,89 & 110,17 & 84,13 \\
\hline 2014 & 9655,6 & 53 & 182,18 & 63 & 6886,89 & 140,20 & 84,13 \\
\hline 2015 & 3577,7 & 51 & 70,15 & 63 & 6886,89 & 51,95 & 80,95 \\
\hline 2016 & 3949,5 & 51 & 77,44 & 63 & 6886,89 & 57,35 & 80,95 \\
\hline 2017 & 3347,8 & 53 & 63,17 & 63 & 6886,89 & 48,61 & 84,13 \\
\hline
\end{tabular}

KESIMPULAN

Berdasarkan analisis dan pembahasan maka disimpulkan sebagai berikut :

1. Sea surface temperature (SST) pada Bulan Februari dan Maret ikan pelagis kecil di perairan Kabupaten Barru menyukai perairan hangat dengan rentang SST $28,61{ }^{\circ} \mathrm{C}-29,7{ }^{\circ} \mathrm{C}$ dan perairan dengan produktivitas tinggi dengan kisaran Klorofil-a yaitu 0,44 $0,94 \mathrm{mg} / \mathrm{m}^{3}$. Hasil tangkapan tertinggi di dapatkan pada Bulan Maret berada 
pada perairan Kabupaten Barru bagian Barat yaitu 1391 - $2060 \mathrm{Kg}$.

2. Tingkat pemanfaatan (Tp) Ikan teri di kabupaten barru 10 tahun terakhir yaitu tahun 2008 - 2017 belum melewati JTB sehingga masih perlu ditingkatkan pemanfaatannya.

\section{SARAN}

Adapun saran yang dianjurkan dalam penelitian ini yaitu untuk meningkatkan perbaikan daerah potesial penangkapan dapat dilakukan dengan melaksanakan peraturan penggunakaan logbook lebih optimal untuk mendapatkan informasi tentang kegiatan penangkapan yang lebi baik.

\section{UCAPAN TERIMA KASIH}

Penulis ingin berterima kasih sebesar-besarnya dan memberikan penghargaan setinggi-tingginya kepada pihak-pihak terkait antara lain :

1. Bapak Dr. Ir. H. Abd Rauf, M.Si selaku pembimbing Utama dan Bapak Dr. Ir. Hasrun, M.Si Selaku pembimbing Anggota.

2. Bapak Dr. Ir. Danial, M.Si, Dr.Ir Ihsan, M.Si, dan Ibu Dr. Ir. Hj. Kasmawati, MP.

3. Orang tuaku tercinta H. Syamsul A. Hamid, Hj. Rosnaeni dan Herlina terima kasih atas segala yang telah dilakukan serta setiap cinta yang terpancar dalam setiap doamu.
4. Saudara dan teman-teman yang selalu mendukung dan membantu dalam menyelesaikan tulisan ini.

\section{DAFTAR PUSTAKA}

Dinas Kelautan dan Perikanan Provinsi Sulawesi Selatan. 2008-2011. Laporan Statistik Perikanan Sulawesi Selatan 2007-2010. Dinas Kelautan dan Perikanan Provinsi Sulawesi Selatan. Makassar.

Jufri, A. 2014. Penentuan Karakteristik Hospot ikan Cakalang di Perairan Teluk Bone. Tesis.

Program Magister Ilmu Perikanan. Fakultas Kelautan dan Perikanan Universitas Hasanuddin. Makassar.

Gulland JA. 1983. Fish Stock Assesment. A Manual of Basic Methods. John Wiley and Sons, Chichester-New York-BrisbaneToronto-Singapore.

Pemerintah Kabupaten Barru. 2013. Profil Kabupaten Barru. http://www.barrukab.go.id/geogr afis. Tanggal akses 18 Mei 2015. Makassar

Sudirman dan Mallawa, A. 2004. Teknik Penangkapan Ikan. Rineka Cipta. Jakarta. 